\title{
Evaluation of difficult airway in paediatric population ranging from 5- 12 years age group
}

\author{
S. Sumer S. ${ }^{1}$, C. Cham S. ${ }^{2}$, M. Raipure A. ${ }^{3 *}$, Dhumane P. ${ }^{4}$ \\ DOI: https://doi.org/10.17511/ijmrr.2019.i05.10
}

\footnotetext{
${ }^{1}$ Sushmita S. Sumer, Senior Resident, Department of Anaesthesiology, Trauma Center GMC, Nagpur, Maharastra, India.

2 Soma C. Cham, Associate Professor, Department of Anaesthesiology, Trauma Center GMC, Nagpur, Maharastra, India.

${ }^{3 *}$ Amrusha M. Raipure, Assistant Professor, Department of Anaesthesiology, Government Medical College, Nagpur, Maharashtra, India.

4 P.G. Dhumane, Professor, Department of Anaesthesiology, Trauma Center GMC, Nagpur, Maharastra, India.
}

Background: The aim of this study is to predict difficult airway on the basis of various airway assessment parameter in the paediatric population between 5-12 years age group. To assess the value of modified Mallampati test (MMT), upper-lip-bite test (ULBT), thyromental distance (TMD), ratio of height to thyromental distance (RHTMD) from which Cormack Lehane grade was derived to predict difficult airway i.e. difficult intubation in paediatric patients ranging from 5-12 years age. Material and Methods: 100 ASA grade I \& II paediatric patients of either sex between the age group of 5-12 years posted for elective surgery under general anaesthesia requiring endotracheal intubation were included in the study. Modified Mallampati test, upper lip bite test, thyromental distance and ratio of height to thyromental distance of the patients were measured and recorded. Results: Modified Mallampati test has the highest sensitivity (75\%) and specificity $(92.05 \%)$ among all the other screening tests. It also has high positive predictive value $(56.25 \%)$, negative predictive value $(96.43 \%)$ and diagnostic accuracy $(90 \%)$. Upper Lip Bite test has high specificity $(79.55 \%)$ and negative predictive value $(93.33 \%)$ with high diagnostic accuracy $(77 \%)$. It has a sensitivity of $58.33 \%$ which is similar to the sensitivity of thyromental distance and ratio of height to thyromental distance. Conclusion: Modified Mallampati test is a useful bedside screening test for predicting difficult intubation in patients between 5-12 years age group. The Upper Lip bite test and thyromental distance has high specificity with high negative predictive value and diagnostic accuracy. The ratio of height to thyromental distance is least useful predictor of airway assessment.

Keywords: Modified Mallampati test (MMT), Upper lip bite test (ULBT, Thyromental distance (TMD), Ratio of Height to TMD (RHTMD)

Corresponding Author

Amrusha M. Raipure, Assistant Professor, Department of Anaesthesiology, Government Medical College, Nagpur, Maharashtra, India.

Email: dramrusha@gmail.com
How to Cite this Article

To Browse
Sumer SS, Cham SC, Raipure AM, Dhumane PG. Evaluation of difficult airway in paediatric population ranging from 5-12 years age group. Int J Med Res Rev. 2019;7(5):411-421.

Available From

https://ijmrr.medresearch.in/index.php/ijmrr/article/ view/1087

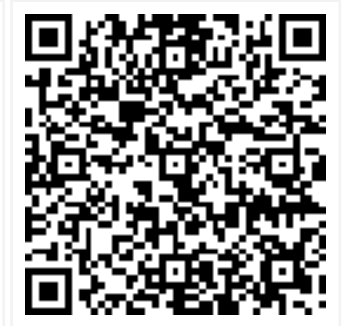

Manuscript Received 2019-08-18

Conflict of Interest No
Review Round 1 2019-08-28

Funding $\mathrm{Nil}$

Review Round 2
2019-09-04
$\begin{gathered}\text { Ethical Approval } \\ \text { Yes }\end{gathered}$

Review Round 3

Accepted 2019-09-09

Plagiarism $X$-checker $9 \%$

(C) 2019 by Sushmita S. Sumer, Soma C. Cham, Amrusha M. Raipure, P.G. Dhumane and Published by Siddharth Health Research and Social Welfare Society. This is an Open Access article licensed under a Creative Commons Attribution 4.0 International License hittps://creativecommons.org/licenses/by/4.0/ unported [CC BY 4.0]. 


\section{Introduction}

Airway management has always been one of the most challenging things faced by the anaesthesiologists. There are numerous challenges (high arched palate, large tonge, less subglottic space etc) associated with the airway management which tests the skill and preparedness of the airway care provider. The fundamental responsibility of an anaesthesiologist is to ensure adequate gas exchange for the patient. Failure to maintain oxygenation for more than few minutes can result in a catastrophic injury $[1,2]$.

The American Society of Anaesthesiologist (ASA) task force has defined difficult endotracheal intubation as "occurring when proper insertion of the tracheal tube requires more than 3 attempts or 10 min". Difficult airway and difficult tracheal intubation are significant etiological factors which results in morbidity and mortality in clinical anaesthesia practice.

Difficult tracheal intubation accounts for $17 \%$ of the respiratory related injuries and results in significant morbidity and mortality. It has been seen that about $28 \%$ of all anaesthesia related deaths are secondary to failure to mask ventilate or intubate [3-5].

Paediatric airway possesses difficulties unique to their age group. Several screening tools for assessing the airway preoperatively has been used in clinical anaesthesia. There is deficient anaesthetic literature regarding tools of airway assessment in paediatric age group $[1,6]$. The importance of predicting a difficult intubation in paediatric age group is more important than in adults because in children the safety margin is very less as they tend to desaturate very rapidly due to their unique physiology. In the paediatric closed claim analysis, respiratory events accounted for $43 \%$ of all the adverse events, most frequently related to inadequate ventilation. In the Paediatric Perioperative Cardiac Arrest registry, $20 \%$ of cardiac arrests were attributed to respiratory complications [1-3].

The evaluation of airway preoperatively can possibly identify a difficult airway. Thus, it will help the anaesthesiologist to anticipate a difficult airway and accordingly make proper airway management plans resulting in better patient care with fewer negative consequences i.e. desaturation, hypoventilation, cardiopulmonary arrest and death [1].
Different predictive tests for difficult laryngoscopy are used in adult patients. The modified Mallampati test (MMT) is a simple airway assessment method and is widely used. The upper lip bite test (ULBT) is another predictive test. The measurement of thyromental distance (TMD) remains widely used.

The ratio of height to TMD (RHTMD) is another method for difficult airway prediction [7-14].

The literature has shown use of different preoperative airway assessment parameters for predicting difficult intubation in adults. However, in pediatric population unlike adults, there are no defined parameters which would help in predicting and recognizing the paediatric patients who are at risk of difficult intubation. The present study aimed to use these tests in paediatric patients to evaluate their usefulness in predicting difficult airway i.e. difficult endotracheal intubation [6].

\section{Materials and Methods}

This Prospective Observational Study "Evaluation of difficult airway in paediatric population ranging from 5-12 years age group" was conducted at a tertiary care hospital after obtaining approval from the Institute Ethics Committee \& after receiving written consent from the parents/ guardian of each child.

\section{Inclusion criteria}

- ASA grade I and II patients.

- Age group: 5-12 years age group.

- Either sex.

- Paediatric patients posted for elective surgery under general anaesthesia.

- Consent

\section{Exclusion criteria}

- No consent.

- ASA grade III \& IV patients.

- Paediatric patients with age less than 5 years and more than 12 years.

- Patients with syndromes having a known difficult airway including congenital upper airway malformation, swellings in head and neck region, scars etc.

- Patients with restricted mouth opening.

- Patients with limitation of cervical movement.

- Uncooperative paediatric patients. 


\section{Methodology}

In the present study, 100 patients were selected belonging to ASA grade I or II of either sex between the age group of 5-12 years posted for elective surgeries requiring general anaesthesia and endotracheal intubation.

All the four parameters upper lip bite test, thyromental distance, ratio of height to thyromental distance and modified Mallampati test were assessed \& recorded preoperatively with the same flexible measuring tape to counter instrumental bias and in a well-lighted room. All the pre-operative airway assessment tests, direct laryngoscopies and intubations were performed by the same (experienced) anaesthesiologist (i.e.one who has done atleast 50 successful paediatric laryngoscopies and intubations)

Modified Mallampati test (MMT): Grade I-Faucial pillars, uvula, soft palate, hard palate visible ,Grade II: - Uvula, soft palate, hard palate visible, Grade III: - Base of uvula or none, soft palate and hard palate visible, Grade IV-Only hard palate visible. Grade I and II were considered as signs of easy intubation. Grade III and IV were considered as signs of difficult intubation Upper Lip Bite test.

Upper lip bite test: Each patient was asked to bite his/her upper lip with incisors of lower jaw and then grading was done as follows:

Class I: Lower incisors can bite the upper lip above the vermilion line. Class II: Lower incisors can bite the upper lip below the vermilion line. Class III: Lower incisors cannot bite the upper lip. Class III was accepted as sign of difficult intubation.

Thyromental distance (TMD) : The patients were asked to fully extend their neck and keep their mouth closed. Then the distance from the mentum to the thyroid notch was measured and recorded.

Ratio of height to thyromental distance (RHTMD): The RHTMD was derived from the height and thyromental distance of the patient.

\section{Cormack-Lehane classification: Direct} laryngoscopic view is divided into 4 grades according to the degree of laryngeal exposure.

The grades are: Grade I - Visualisation of entire laryngeal aperture. Grade II - Visualisation of posterior part of laryngeal aperture. Grade III Visualisation of only epiglottis. Grade IV - No glottis structures can be seen.
Grade I and Grade II are considered as easy intubation. Grade III and IV are considered as difficult intubation [7-14].

Evaluation of the response to intervention: Confirmation of endotracheal intubation was done with capnography. All the paediatric patients were followed up postoperatively and complications like sore throat, hoarseness of voice etc. were noted.

Statistical analysis: Statistical analysis was done using student t-test. SPSS 13.0 software was used to calculate $\mathrm{p}$ value. $\mathrm{P}<0.05$ was taken as statistically significant. A descriptive analysis was done on all variables to obtain a frequency distribution. The mean + SD and ranges were calculated for quantitative variables. Continuous variables were compared by the Student $t$ test.

Proportions were analyzed with the chi-square test. Cut off value of thyromental distance and ratio of height to thyromental distance was calculated by ROC analysis.

\section{Observations}

Table No-1: Demographic data.

\begin{tabular}{|l|l|}
\hline \multicolumn{1}{|c|}{ Age (year) } & \multicolumn{1}{c|}{$\mathbf{7 . 4 9 \pm 2 . 2 5}$} \\
\hline Weight $(\mathrm{kg})$ & $24.03 \pm 5.88$ \\
\hline Height $(\mathrm{cm})$ & $121.5 \pm 11.36$ \\
\hline
\end{tabular}

Table No.-2: Distribution of study population as per $\mathbf{m m t}$.

\begin{tabular}{|l|l|l|}
\hline \multicolumn{1}{|c|}{ Modified Mallampati Test } & Frequency & Percent \\
\hline Grade I (Easy) & 38 & 38.00 \\
\hline Grade II (Easy) & 46 & 46.00 \\
\hline Grade III (Difficult) & 16 & 16.00 \\
\hline Grade IV (Difficult) & 0 & 0 \\
\hline Total & 100 & 100 \\
\hline
\end{tabular}

Table No.-3: Distribution of study population as per ulbt

\begin{tabular}{|l|l|l|}
\hline \multicolumn{1}{|c|}{ Upper Lip Bite Test } & Frequency & \multicolumn{1}{c|}{ Percent } \\
\hline Class I (Easy) & 34 & 34.00 \\
\hline Class II (Easy) & 41 & 41.00 \\
\hline Class III (Difficult) & 25 & 25.00 \\
\hline Total & 100 & 100.00 \\
\hline
\end{tabular}

Table No.-4: Distribution of study population as per tmd $(\mathrm{cm})$ :

\begin{tabular}{|l|l|l|}
\hline \multicolumn{1}{|c|}{ TMD $(\mathrm{cm})$} & \multicolumn{1}{c|}{ Frequency } & \multicolumn{1}{c|}{ Percent } \\
\hline Easy & 63 & 63.00 \\
\hline Difficult & 37 & 37.00 \\
\hline Total & 100 & 100.00 \\
\hline
\end{tabular}


Table No.-5: Distribution of study population as per rhtmd $(\mathbf{c m})$

\begin{tabular}{|l|l|l|}
\hline \multicolumn{1}{|c|}{ RHTMD } & \multicolumn{1}{c|}{ Frequency } & \multicolumn{1}{c|}{ Percent } \\
\hline Easy & 63 & 63.00 \\
\hline Difficult & 37 & 37.00 \\
\hline Total & 100 & 100.00 \\
\hline
\end{tabular}

Table No.-6: Distribution of study population on the basis of cormack lehane grading:

\begin{tabular}{|l|l|l|}
\hline \multicolumn{1}{|c|}{ Cormack Lehane Grading (C.L) } & Frequency & Percent \\
\hline C.L. Grade I (Easy) & 52 & 52 \\
\hline C.L. Grade II (Easy) & 36 & 36 \\
\hline C.L. Grade III (Difficult) & 12 & 12 \\
\hline C.L. Grade IV (Difficult) & 00 & 0 \\
\hline Total & 100 & 100 \\
\hline
\end{tabular}

Table No.7(a): Association among study population between $\mathrm{mmt}$ and cormack lehane's grading:

\begin{tabular}{|l|l|l|l|l|}
\hline \multicolumn{2}{|c|}{ MMT } & \multicolumn{2}{c|}{ CL } & \multirow{2}{*}{ Total } \\
\cline { 3 - 4 } \multicolumn{2}{|c|}{} & Easy & Difficult & \\
\hline \multirow{3}{*}{ Easy } & No. & 81 & 3 & 84 \\
\cline { 2 - 5 } & $\%$ & 92.04 & 25.00 & $84.00 \%$ \\
\hline \multirow{3}{*}{ Difficult } & No. & 7 & 9 & 16 \\
\cline { 2 - 5 } & $\%$ & 7.95 & 75.00 & 16.00 \\
\hline \multirow{2}{*}{ Total } & No. & 88 & 12 & 100 \\
\cline { 2 - 5 } & $\%$ & 100 & 100 & 100.00 \\
\hline
\end{tabular}

Table No.-7(b): Shows sensitivity, specificity, positive predictive value, negative predictive value of $\mathbf{~ m m t}$

\begin{tabular}{|l|l|l|l|}
\hline \multirow{2}{*}{ Measure } & \multirow{2}{*}{ Estimate } & \multicolumn{2}{c|}{$95 \%$ confidence interval } \\
\cline { 3 - 4 } & & Lower & Upper \\
\hline Sensitivity & $75.00 \%$ & 46.77 & 91.11 \\
\hline Specificity & $92.05 \%$ & 84.48 & 96.09 \\
\hline Positive predictive value & $56.25 \%$ & 33.18 & 76.9 \\
\hline Negative predictive value & $96.43 \%$ & $90.02 \%$ & $98.78 \%$ \\
\hline Diagnostic accuracy & $90 \%$ & $82.56 \%$ & $94.48 \%$ \\
\hline
\end{tabular}

Table No. 8(a): Association among study population between ulbt and cormack lehane's grading:

\begin{tabular}{|l|l|l|l|l|}
\hline \multicolumn{2}{|c|}{ ULBT } & \multicolumn{2}{c|}{ CL } & \multirow{2}{*}{ Total } \\
\cline { 2 - 4 } \multicolumn{2}{|c|}{} & Easy & Difficult & \\
\hline \multirow{3}{*}{ Easy } & No. & 70 & 5 & 75 \\
\cline { 2 - 5 } & $\%$ & $79.55 \%$ & $41.67 \%$ & $75.00 \%$ \\
\hline \multirow{3}{*}{ Difficult } & No. & 18 & 7 & 25 \\
\cline { 2 - 5 } & $\%$ & $20.45 \%$ & $58.33 \%$ & $25.00 \%$ \\
\hline \multirow{2}{*}{ Total } & No. & 88 & 12 & 100 \\
\cline { 2 - 5 } & $\%$ & $100 \%$ & $100 \%$ & $100 \%$ \\
\hline
\end{tabular}

Table-8 (b): Shows sensitivity, specificity, positive predictive value, negative predictive value of ulbt:

\begin{tabular}{|l|l|l|l|}
\hline \multirow{2}{*}{ Measure } & \multirow{2}{*}{ Estimate } & \multicolumn{2}{c|}{$95 \%$ confidence interval } \\
\cline { 3 - 4 } & & Lower & Upper \\
\hline Sensitivity & $58.33 \%$ & $31.95 \%$ & $80.67 \%$ \\
\hline Specificity & $79.55 \%$ & $69.97 \%$ & $86.65 \%$ \\
\hline Positive Predictive Value & $28.00 \%$ & $14.28 \%$ & $47.58 \%$ \\
\hline Negative Predictive Value & $93.33 \%$ & $85.32 \%$ & $97.12 \%$ \\
\hline Diagnostic Accuracy & $77.00 \%$ & $67.85 \%$ & $84.16 \%$ \\
\hline
\end{tabular}

Table No.-9(a): Association among study population between $\operatorname{tmd}(\mathrm{cm})$ and cormack lehane's grading:

\begin{tabular}{|l|l|l|l|l|}
\hline \multicolumn{2}{|c|}{ TMD } & \multicolumn{2}{c|}{ CL } & \multirow{2}{*}{ Total } \\
\cline { 3 - 5 } \multicolumn{2}{|c|}{} & Easy & Difficult & \\
\hline \multirow{3}{*}{ Easy } & No. & 58 & 5 & 63 \\
\cline { 2 - 5 } & $\%$ & $65.90 \%$ & $41.66 \%$ & $63.00 \%$ \\
\hline \multirow{2}{*}{ Difficult } & No. & 30 & 7 & 37 \\
\cline { 2 - 5 } & $\%$ & $34.09 \%$ & $58.33 \%$ & $37.00 \%$ \\
\hline \multirow{3}{*}{ Total } & No. & 88 & 12 & 100 \\
\cline { 2 - 4 } & $\%$ & $100 \%$ & $100 \%$ & $100.00 \%$ \\
\hline
\end{tabular}

Table No.-9(b): Shows sensitivity, specificity, positive predictive value, negative predictive value of tmd:

\begin{tabular}{|l|l|l|l|}
\hline \multirow{2}{*}{ Measure } & \multirow{2}{*}{ Estimate } & \multicolumn{2}{c|}{$95 \%$ confidence interval } \\
\cline { 3 - 4 } & & Lower & Upper \\
\hline Sensitivity & $58.33 \%$ & $30.43 \%$ & $66.22 \%$ \\
\hline Specificity & $65.90 \%$ & $56.00 \%$ & $75.81 \%$ \\
\hline Positive Predictive Value & $18.91 \%$ & $6.29 \%$ & $31.53 \%$ \\
\hline Negative Predictive Value & $92.06 \%$ & $85.38 \%$ & $98.73 \%$ \\
\hline Diagnostic Accuracy & $65.00 \%$ & $53.00 \%$ & $74.16 \%$ \\
\hline
\end{tabular}

Table No.-10(a): Association among study population between rhtmd and cormack lehane's grading:

\begin{tabular}{|l|l|l|l|l|}
\hline \multicolumn{2}{|c|}{ RHTMD } & \multicolumn{2}{c|}{ CL } & \multirow{2}{*}{ Total } \\
\cline { 3 - 4 } \multicolumn{2}{c|}{} & Easy & Difficult & \\
\hline \multirow{3}{*}{ Easy } & No. & 41 & 5 & 46 \\
\cline { 2 - 5 } & $\%$ & $46.59 \%$ & $41.66 \%$ & $60.00 \%$ \\
\hline \multirow{3}{*}{ Difficult } & No. & 47 & 7 & 54 \\
\cline { 2 - 5 } & $\%$ & $53.40 \%$ & $58.33 \%$ & $40.00 \%$ \\
\hline \multirow{2}{*}{ Total } & No. & 88 & 12 & 100 \\
\cline { 2 - 4 } & $\%$ & $100 \%$ & $100 \%$ & $100.00 \%$ \\
\hline
\end{tabular}

Table No.-10 (B): shows sensitivity, specificity, positive predictive value, negative predictive value of RHTMD:

\begin{tabular}{|l|l|l|l|}
\hline \multirow{2}{*}{ Measure } & \multirow{2}{*}{ Estimate } & \multicolumn{2}{c|}{$95 \%$ confidence interval } \\
\cline { 3 - 4 } & & Lower & Upper \\
\hline Sensitivity & $58.33 \%$ & $31.95 \%$ & $80.67 \%$ \\
\hline Specificity & $46.59 \%$ & $36.53 \%$ & $56.94 \%$ \\
\hline Positive predictive value & $12.96 \%$ & $6.42 \%$ & $24.42 \%$ \\
\hline Negative predictive value & $89.13 \%$ & $76.96 \%$ & $95.27 \%$ \\
\hline Diagnostic accuracy & $48.00 \%$ & $38.23 \%$ & $54.30 \%$ \\
\hline
\end{tabular}


Table No.-11: $P$ value of MMT, ULBT, TMD, RHTMD:

\begin{tabular}{|l|l|}
\hline \multicolumn{1}{|c|}{ Tests } & \multicolumn{1}{|c|}{ C.L. grade (P value) } \\
\hline MMT & $<0.0001$ \\
\hline ULBT & 0.0067 \\
\hline TMD & $<0.0001$ \\
\hline RHTMD & $<0.0001$ \\
\hline
\end{tabular}

\section{Results}

In the present study there were 58 males and 42 female paediatric patients. 55 patients belonged to ASA grade I, 45 patients belonged to ASA grade II. Modified Mallampati test, upper lip bite test, thyromental distance and ratio of height to thyromental distance were assessed preoperatively and then difficulty in intubation was assessed using the Cormack Lehane classification. Statistically significant correlation was found between modified Mallampati test, upper lip bite test, thyromental distance, ratio of height to thyromental distance and the Cormack Lehane classification. In the present study, it was observed that Modified Mallampati test had the highest sensitivity (75\%) and specificity $(92.05 \%)$ among all the other screening tests. It also had high positive predictive value (56.25\%), negative predictive value (96.43\%) and diagnostic accuracy (90\%). Upper Lip Bite test had high specificity $(79.55 \%)$ and negative predictive value (93.33\%) with high diagnostic accuracy (77\%). It had a sensitivity of $58.33 \%$ which was similar to the sensitivity of thyromental distance and ratio of height to thyromental distance. Thyromental distance had high specificity $(65.90 \%)$ with high negative predictive value $(92.06 \%)$. Ratio of height to thyromental distance had sensitivity with high negative predictive value $(89.13 \%)$. Ratio of height to thyromental distance had the lowest positive predictive value (12.96\%).

\section{Discussion}

Securing the airway is an integral part of general anaesthesia. Airway management therefore always remains a primary concern for the anaesthesiologists [4]. Major complications of airway management are rare but may be life threatening $A$ thorough and focused assessment of the airway prior to the planned administration of anaesthesia is of vital importance. Airway assessment forms the first part of any airway management strategy leading to planning of drugs, equipment and techniques to be used [15-17].
Preoperative airway assessment helps in detection of patients at risk of difficult intubation and accordingly make proper airway management plans which can be instituted immediately prior to induction of anaesthesia resulting in better patient care with fewer negative outcomes like desaturation, hypoventilation, and cardiopulmonary arrest [1].

The incidence of difficult intubation in children has been reported as $3.4 \%$ [8]. Failure to maintain a patent airway or failed tracheal intubation is the primary cause of anaesthesia related morbidity and mortality [18-21].

Several clinical tests like the modified Mallampati test, Wilson risk score, interincisor distance, thyromental distance, ratio of height to thyromental distance, upper lip bite test, sternomental distance have been proposed for preoperatively identifying the patients who may have difficulty in laryngoscopy and intubation, but there is no single test or group of tests that can accurately predict a difficult airway.

Hence the need for a single or group of predictive tests that has the ease of applicability and accuracy of prediction power persists. An ideal preoperative airway assessment test should be highly sensitive to identify maximum number of patients with difficult intubation correctly and also highly specific to avoid false negative results.

The test should also have high positive predictive value with less negative predictive value [15].

There has been extensive research done on various parameters for predicting difficulty in intubation, including clinical anthropological measurements, radiological imaging etc. but almost all of them are far from being ideal when used as a sole identifying parameter [6].

Several non-invasive clinical preoperative tests and parameters have been proposed, studied and described as predictors of difficult intubation in adults. A significant association is seen between the non-invasive clinical predictors of airway assessment and difficult tracheal intubation [6].

However, there is very minimal data available for the use of these predictive tests in infants and young children to detect difficult intubation in children 1. Certain age-related anatomical characteristics make laryngoscopy and endotracheal intubation difficult in paediatric population as compared to adults [8]. 
A review of the paediatric closed claims cases stated that most common causes of anaesthesia related deaths were result of inadequate ventilation. Inadequate ventilation was a more common problem in children than in adults [21].

In 2012, Aggarwal et al [22] conducted a study in 100 patients of either sex between the age group of 1-5 years scheduled for elective surgery under general anaesthesia to evaluate difficult airway predictors in paediatric population. They concluded that interincisor gap, neck circumference, sternomental distance are predictors of difficult mask ventilation. Age, best oropharangeal view and thyromental distance are found to be predictors of difficult laryngoscopy and intubation.

In 2014, Mehmet Turan et al [23] conducted a study in 250 paediatric patients posted for elective surgery under general anaesthesia to compare the different airway assessment tests to predict difficult intubation. They performed modified Mallampati test, upper lip bite test, thyromental distance \& ratio of height to thyromental distance calculation preoperatively and compared it with Cormack Lehane grading after doing direct laryngoscopy. Their found that the modified Mallampati test and upper lip bite test may be useful in paediatric patients for predicting difficult intubation.

For the present study, the modified Mallampati test, upper lip bite test, thyromental distance and ratio of height to thyromental distance were selected, as these tests are easy to perform, easy to understand, patient friendly and there are no complicated techniques involved. The aim of the present study was to predict difficult intubation in paediatric patients between 5-12 years age group \&to correlate the tests with the laryngoscopic view by using the Cormack Lehane's classification. Cormack Lehane grading is considered as the "gold standard" for predicting the difficult intubation [2].

The efficacy of these tests was evaluated in terms of Sensitivity, Specificity, Positive predictive Value (PPV) and Negative predictive value (NPV) and diagnostic accuracy [1].

Modified Mallampati Test (MMT): In the present study, the sensitivity \& specificity of MMT was found to be $75 \% \& 92.05 \%$ respectively, and the positive $\&$ negative predictive value $56.25 \%$ \& $96.43 \%$ respectively. The diagnostic accuracy was found to be $90.00 \%$.
The above results give an impression that by using MMT one can correctly identify all the patients with easy intubation and chances are rare for that case to be difficult. It may also be useful for predicting difficult intubation. However, the absence of a difficult MMT will not rule out completely the presence of a difficult intubation.

The present study results for MMT are comparable to the study conducted by Mehmet Turan et al [23] in 250 paediatric patients who concluded that the specificity and negative predictive value of MMT was more than the sensitivity and positive predictive value. They also found MMT as the most sensitive test among all the four tests a finding which is same as the present study.

Kopp et al [24] studied the utility of Mallampati classification for predicting difficult intubation in children where they mentioned that the specificity of modified Mallampati test (MMT) was more than sensitivity. This correlates with our findings. In the present study MMT has high specificity and negative predictive value with minimum positive predictive value. It also has the highest sensitivity among all the other tests.

Upper Lip Bite Test (ULBT): In the present study the sensitivity of ULBT was found to be $58.33 \%$, the specificity was found to be $79.55 \%$, positive predictive value was found to be $28.00 \%$, the negative predictive value was found to be $93.33 \%$, and the diagnostic accuracy of ULBT was found to be $77.00 \%$.

The above results show that ULBT may be useful for predicting easy intubations. It may also predict difficult intubation however the absence of a difficult ULBT grading will not rule out completely the presence of a difficult intubation. Like the present study, Khan et al also concluded that ULBT is an acceptable option for predicting difficult intubation [8].

The findings of the present study are comparable to the findings of the study conducted by Mehmet Turan et al [23] where they also found high specificity and negative predictive value of ULBT $97.32 \%$ and $96.5 \%$ respectively, with low sensitivity $69.23 \%$ and positive predictive value $75 \%$. The ULBT evaluates a combination of jaw subluxation and the presence of buck teeth concurrently, apparently increasing its predictive value and reliability. Considering that the ULBT is a simple objective evaluation that is not dependent on particular circumstances or specific instruments, 
It is of utmost importance to evaluate and reevaluate it in various conditions and make comparisons with alternative tests. But in the present study the major disadvantage was making the paediatric patients understand and perform the test.

Thyromental Distance (TMD): This test is very simple and doesn't have inter observer variability that is seen in MMT. In the present study the sensitivity of TMD was found to be $58.33 \%$, the specificity - $65.90 \%$, the positive predictive value $18.9 \%$, negative predictive value $-92.06 \%$ and the diagnostic accuracy of TMD was found to be $65 \%$. The above results show that TMD can predict easy intubations out of which rarely a few may be difficult. It may also be useful for predicting a difficult intubation. Salimi et al [25] in their study in adults compared ULBT with TMD and reported that ULBT has higher specificity and positive predictive value than TMD. This finding is same as the present study.

In adults, the minimal TMD below which the intubation is found to be difficult is $6.5 \mathrm{~cm}$ as per most studies. In infants and children, however there is no fixed values available on the lowest acceptable value for TMD because of racial and ethnic differences in paediatric population, although it will be generally smaller. It is reported that the range of TMD is 4.1-5.8 cm in Chinese children aged 4-12 years.

In the study conducted by Mehmet Turan et al [23] in paediatric patients they found the cut off value for TMD as $5.5 \mathrm{~cm}$. In the present study it was found that the cut off value to be $6.3 \mathrm{~cm}$ through ROC curve analysis i.e. TMD of less than $6 \mathrm{~cm}$ is more likely to be associated with difficult laryngoscopy and intubation. This difference in the minimal acceptable value of TMD could be because of racial characteristics. Brodsky et al [26] in their study in concluded that the wide variation in the values of TMD can be due to the differences in the anthropological measurements of different races and ethnicities associated with ethnic variation in craniofacial configuration of populations. In the present study TMD has high specificity (65.90\%) and negative predictive value $(92.06 \%)$ with minimum positive predictive value (18.9\%).

Ratio of Height to Thyromental distance (RHTMD): The final parameter used in the present study was ratio of height to thyromental distance.
In the present study the sensitivity of ratio of height to thyromental distance was found to be $58.33 \%$, the specificity was found to be $46.59 \% \%$, positive predictive value was found to be $12.96 \%$, negative predictive value was found to be $89.13 \%$ and the diagnostic accuracy was found to be $48 \%$. It was observed that a cut off value of $18 \mathrm{~cm}$ for ratio of height to thyromental distance in the present study through ROC curve analysis.

The above results show that RHTMD can predict difficult intubation out of which there are less chances of it being easy, however if it predicts easy intubation, there may be high chances of that to be difficult. The diagnostic accuracy of this test is also less among all the other tests.

Mehmet Turan et al [23] in their study found the optimal cut off value of RHTMD to be $23.5 \mathrm{~cm}$ with a sensitivity of $57.69 \%$, specificity of $86.61 \%$, Positive Predictive Value of $48.6 \%$, Negative predictive value of $90.3 \%$ and the diagnostic accuracy was $62.4 \%$. The difference in the cut off value in the present study may be due to anthropological variations in various groups and ethnicities.

Safavi et al [27] in their study on 603 adult subjects for comparing ULBT, RHTMD with MMT for difficult laryngoscopy and intubation found that RHTMD has some limitations. It depends on accurate measurement of patient's TMD and height that lessens simplicity of this method. Also, the cutoff point of RHTMD for prediction of difficult laryngoscopy is race dependent. The RHTMD cut off point equal to $21.06 \mathrm{~cm}$ may not be applicable in the other population. So, they recommended calculating cutoff point for each population separately.

Krobbuaban et al [28] conducted a study in 550 patients aged above $18 y$ rs to compare TMD and RHTMD with Cormack Lehane grading. They found a cut off value for RHTMD to be $23.5 \mathrm{~cm}$ which was different from the cut off value of $25 \mathrm{~cm}$ reported in previous studies $[29,30,31]$. They suggested that the difference is small, and further investigation is required to determine the significance of ethnicity.

In the present study RHTMD has high sensitivity, high negative predictive value with low specificity, positive predictive value and diagnostic accuracy. Thus, based on the present results it would be recommended that modified Mallampati test as a useful screening test for identifying a difficult airway (difficult intubation) in paediatric patients. 


\section{Limitations \& Recommenda - tions of the present study}

1) The present study was conducted at only one tertiary care centre, so it is recommend a multicentric study in future.

2) The present study included only ASA grade I and II patients posted for elective surgery under general anaesthesia. So, it is recommended study using the screening tests used in the present study for prediction of difficult airway in ASA grade III and grade IV patients and emergency cases also so as to reduce the incidences of airway catastrophe in emergency situations.

3) Inter-observer variation bias cannot be ruled out; hence it is recommended that all the observations should be noted by a single anaesthesiologist.

4) Authors recommend a study with a larger patient population by taking into consideration the screening tests used in the present study so as to rule out racial, ethnic and regional variations.

5) Author recommend a study using the screening tests used in the present study in conjunction with other tests of airway assessment viz. sternomental distance, hyomental distance, inter incisor distance etc. to predict difficult airway which may prove to be a better predictor of difficult intubation.

\section{Conclusion}

Modified Mallampati test is the most sensitive test with the highest accuracy. Thus, it may be a useful bedside screening test for predicting difficult intubation in patients between 5-12 years age group. The Upper Lip bite test has high specificity with high negative predictive value and diagnostic accuracy. The thyromental distance also has high specificity with high negative predictive and diagnostic accuracy. The ratio of height to thyromental distance is least useful for prediction of difficult intubation in paediatric patients with low sensitivity, specificity, positive predictive value and diagnostic accuracy.

\section{What this study adds to existing knowledge?}

Modified Mallampati test, upper lip bite test and thyromental distance are useful screening tests for predicting difficult intubation in paediatric patients.

\section{Author's contribution}

Dr. Sushmita S. Sumer: Concept and Data collection

Dr. Soma C. Cham: Data Analysis and Discussion

Dr. Amrusha M. Raipure: Data Analysis and Discussion

Dr. P.G. Dhumane: Supervised the study.

\section{Reference}

01. Jain RR, Rabb MF. The difficult paediatric airway, In- Hageberg CA, Benumof and Hageberg's Airway management. 3rd ed, PhiladelphiaElsevier Saunders. 2013;723-60.

[Crossref]

02. Ramachandran SK, Klock Jr PA. Definition and incidence of the difficult airway, In Benum of and Hagberg's airway management. WB Saunders. 2013;201-208.

[Crossref]

03. American Society of Anesthesiologists Task Force on Management of the Difficult Airway. Practice guidelines for management of the difficult airway- an updated report by the American Society of Anesthesiologists Task Force on Management of the Difficult Airway. Anesthesiol. 2003;98(5)1269-1277.

doi: $10.1097 / 00000542-200305000-00032$ [Crossref]

04. Larson SL, Jordan L. Preventable adverse pati ent outcomes- a closed claims analysis of res piratory incidents. AANA J. 2001;69(5)386-92. [Crossref]

05. Gupta S, Sharma R, Jain D. Airway assessmentpredictors of difficult airway. Indian J Anaesth. 2005;49(4)257-262.

[Crossref]

06. Rafique NB, Khan FA. Comparison of Mallampatti test, thyromental distance and distance from tra gus to nares for predicting difficult intubation in pediatric patients. Open J Anesthesiol. 2014;4
(4)104-9.
doi:
10.4236/ojanes.2014.44016
[Crossref]

07. Mallampati SR, Gatt SP, Gugino LD, Desai SP, Waraksa B, Freiberger $D$, et al. A clinical sign to predict difficult tracheal intubation- a prospecti ve study. Can Anaesth Soc J. 1985;32(4)42934. doi: $10.1007 / \mathrm{bf03011357 \text {[Crossref] }}$ 
08. Khan ZH, Kashfi A, Ebrahimkhani E. A comparison of the upper lip bite test (a simple new technique) with modified Mallampati classification in predicting difficulty in endotracheal intubation- a prospective blinded study. Anesth Analg. 2003;96(2)595-599. doi: 10.1097/00000539-200302000-00053 [Crossref]

09. Salimi A, Farzanegan B, Rastegarpour A, Kolahi $A A$. Comparison of the upper lip bite test with measurement of thyromental distance for prediction of difficult intubations. Acta Anaesthesiol Taiwan. 2008;46(2)61-65.

doi: $10.1016 / \mathrm{S} 1875-4597(08) 60027-2$ [Crossref]

10. Krobbuaban B, Diregpoke S, Kumkeaw S, Tanomsat $M$. The predictive value of the height ratio and thyromental distance- four predictive tests for difficult laryngoscopy. Anesth Analg. 2005;101(5)1542-1545.

doi: $\quad$ 10.1213/01.ANE.0000181000.43971.1E [Crossref]

11. Eberhart LH, Arndt C, Cierpka T, Schwanekamp J, Wulf $\mathrm{H}$, Putzke $\mathrm{C}$. The reliability and validity of the upper lip bite test compared with the Mallampati classification to predict difficult laryngoscopy- an external prospective evaluation. Anesth Analg. 2005;101(1)284-289. doi: $\quad$ 10.1213/01.ANE.0000154535.33429.36 [Crossref]

12. Hester CE, Dietrich SA, White SW, Secrest JA, Lindgren KR, Smith T. A comparison of preoperative airway assessment techniques- the modified Mallampati and the upper lip bite test. AANA J. 2007;75(3)177-182.

[Crossref]

13. Mehta T, Jayaprakash J, Shah V. Diagnostic value of different screening tests in isolation or combination for predicting difficult intubation- $A$ prospective study. Indian journal of anaesthesia. 2014;58(6)754-757.

doi: 10.4103/0019-5049.147176 [Crossref]

14. Karkouti K, Rose DK, Ferris LE, Wigglesworth DF, Meisami-Fard $T$, Lee $H$. Inter-observer reliability of ten tests used for predicting difficult tracheal intubation. Can J Anaesth. $1996 ; 43(6) 554-559$.

doi: $10.1007 / B F 03011765$ [Crossref]
15. Schmitt HJ, Kirmse M, Radespiel-Troger M. Ratio of patient's height to thyromental distance improves prediction of difficult laryngoscopy. Anaesth Intensive Care. 2002;30(6)763-765.

doi: 10.1177/0310057X0203000607 [Crossref]

16. Cormack RS, Lehane J. Difficult tracheal intubation in obstetrics. Anaesthes. $1984 ; 39(11) 1105-1111$.

doi: $10.1111 /$ j.1365-2044.1984.tb08932.x [Crossref]

17. Savva D. Prediction of difficult tracheal intubation. Br J Anaesth. 1994;73(2)149-153.

doi: $10.1093 / \mathrm{bja} / 73.2 .149$ [Crossref]

18. Rucker JC, Cole D, Guerina LR, Zoran N, Chung $F$, Friedman $Z$. A prospective observational evaluation of an anatomically guided, logically formulated airway measure to predict difficult laryngoscopy. Eur J Anaesthesiol. 2012;29(5)213-217.

doi: 10.1097/EJA.0b013e3283502168 [Crossref]

19. Adamus M, Fritscherova $S$, Hrabalek $L$, Gabrhelik T, Zapletalova J, Janout V. Mallampati test as a predi-ctor of laryngoscopic view. Biomed Pap Med Fac Univ Palacky Olomouc Czech Repub. 2010;154(4)339-343.

[Crossref]

20. Kim WH, Ahn HJ, Lee CJ, Shin BS, Ko JS, Choi SJ, et al. Neck circumference to thyromental distance ratio- a new predictor of difficult intubation in obese patients. $\mathrm{Br} \mathrm{J}$ Anaesth. $2011 ; 106(5) 743-748$.

doi: $10.1093 / \mathrm{bja} / \mathrm{aer024}$ [Crossref]

21. Cheney FW, Posner KL, Lee LA, Caplan RA, Domino KB. Trends in anesthesia-related death and brain damage- A closed claims analysis. Anesthesiol. 2006;105(6)1081-1086. doi: $10.1097 / 00000542-200612000-00007$ [Crossref]

22. Aggarwal A, Sharma KR, Verma UC. Evaluation of difficult Airway predictors in pediatric population as a clinical investigation. J Anesth Clin Res. 2012;3(11)1-5.

doi: $\quad 10.4172 / 2155-6148.1000256 \quad$ [Crossref] 
23. Inal $M T$, Memiş $D$, Sahin $S H$, Gunday $I$. Comparison of different tests to determine difficult intubation in pediatric patients. Rev Bras Anestesiol. 2014;64(6)391-394.

doi: $10.1016 / j . b j a n .2014 .02 .001$ [Crossref]

24. Valley RD, Freid EB, Bailey AG, Kopp VJ, Georges LS, Fletcher $J$, et al. Tracheal extubation of deeply anesthetized pediatric patients- a comparison of desflurane and sevoflurane. Anesth Analg. 2003;96(5)13201324.

doi: $\quad$ 10.1213/01.ane.0000058844.77403.16

[Crossref]

25. Salimi A, Farzanegan B, Rastegarpour A, Kolahi $A A$. Comparison of the upper lip bite test with measurement of thyromental distance for prediction of difficult intubations. Acta Anaesthesiol Taiwan. 2008;46(2)61-65.

doi: $10.1016 / \mathrm{S} 1875-4597(08) 60027-2$ [Crossref]

26. Brodsky JB, Lemmens HJ, Brock-Utne JG, Vierra M, Saidman LJ. Morbid obesity and tracheal intubation. Anesth Analg. 2002;94(3)732-736. doi: 10.1097/00000539-200203000-00047 [Crossref]
27. Safavi M, Honarmand A, Zare N. A comparison of the ratio of patient's height to thyromental distance with the modified Mallampati and the upper lip bite test in predicting difficult laryngoscopy. Saudi J Anaesth. 2011;5(3)258263.

doi: $10.4103 / 1658-354 X .84098$ [Crossref]

28. Krobbuaban B, Diregpoke S, Kumkeaw S, Tanomsat $M$. The predictive value of the height ratio and thyromental distance- four predictive tests for difficult laryngoscopy. Anesth Analg. 2005;101(5)1542-1545.

doi: $\quad$ 10.1213/01.ANE.0000181000.43971.1E [Crossref]

29. Khan RM. Airway management. 6th ed, Hyderabad- Paras medical publisher. 2018. [Crossref]

30. Ayoub C, Baraka A, el-Khatib M, Muallem M, Kawkabani N, Soueide A. A new cut-off point of thyromental distance for prediction of difficult airway. Middle East J Anaesthesiol. 2000;15(6)619-633.

[Crossref]

31. Frerk CM. Predicting difficult intubation. Anaesthesia. 1991;46(12)1005-1008.

doi: 10.1111/j.1365-2044.1991.tb09909.x [Crossref] 